\title{
ATTITUDE OF STUDENTS TOWARDS ERUDITION OF VOCABULARY AND VERBAL APTITUDE USING COMPUTER TECHNOLOGY AND INTERNET
}

\author{
K. RATHIGA \\ Department of English Mepco Schlenk Engineering College, Sivakasi, India
}

\begin{abstract}
India, with a concoction of languages at its hand, finds itself at a verge of imperative learning of English. The necessity of acquiring English forward the thirst of English language learning, incorporated with comfortable learning zones and solutions using computer technology. The paper focuses on converging computer technology to embark the aptitude tests, which the engineering students have to encounter in the first phase of interview structured by almost all the recruiting sources. To cosset this stipulation, the students should have the silage of words that foster their responding to internet or intranet verbal tests that are time bound. With this standing, the participants of the research are primed for the actuality that verbal ability tests are not only beneficial for placement, but also to outshine in GRE, GMAT, UPSE Exams, bank exams and other competitive Examinations. The participants are administered with verbal ability tests sporadically for four months and they fashioned the affirmative feedback that a higher verbal ability is assimilated through the computer aided training resulting in the fortified confidence to surmount the verbal tests posted by the interview panel, and to communicate assertively in English, as they have accomplished exceptional English grammar and vocabulary. The participants learnt English constructively using computer technology due to the quality and quantity of the content, speed, time consuming, a variety of exercises, the immediate feedback/result received, and access to native speakers, selflearning, appealing aspects like color, graphics, animation, picture etc..... English language students find computer technology as a good learning tool to improve vocabulary and acquiring verbal skills.
\end{abstract}

KEYWORDS: Computer Aided Language Learning, Verbal Ability, Vocabulary \& Self-Learning

Received: May 02, 2017; Accepted: May 22, 2017; Published: Jun 05, 2017; Paper Id.: IJELJUN20179

\section{INTRODUCTION}

In India, English shares blanket with native languages and masks the autonomous temperament of those languages. India, with a concoction of languages at its hand, finds itself at a verge of imperative learning of English. This necessity of acquiring English forward the thirst of English language learning incorporating the comfortable learning zones and learning solutions using technology. "College English teachers have to fully recognize the importance and significance of deepening College English. As the symbol of modern language teaching, CALL (Computer Assisted Language Learning) has led college English teaching into the new development phase. The recognition that foreign language teaching has exceptionally close relationship with the educational technology application has become a consensus. The renewal of educational concept interacts with the development of educational technology, taking on the new trend of integration"[1]. The language lab is a technological boom offering outcome oriented teaching methodologies as well as enriched language learning process. Computer-assisted language learning can rally round learners improving their language skills very fast with involvement and curiosity. It has the ability to create both independent and collaborative learning environments, in which students can acquire and practice a new language. It makes the learners study their lessons 
at their own pace and speed, and achieve immediate feedback. So, in the last ten years educational circles have witnessed a dramatic shift from seeing the computer as an adjunct or source of supplemental educational material for treating it as a platform where effective teaching/learning can be promoted. (Warschauer, 1996). [2]

The aim of this research is, to investigate the attitude of the students in using computers in enriching vocabulary and learning verbal ability. This research manifested from the problems faced by the Engineering students, who are generally exposed to the aptitude tests by almost all the recruiting sources in the first phase of the interview. The quantitative and verbal aptitude tests are administrated to the students, which they find challenging. The students are confident to certain extent with quantitative aptitude and related procedure with formula where as they are totally confounded with verbal aptitude. The department of English is always given the charge of imparting verbal training to the students that make the youth scratch their brain leading to the unpleasant learning experience. Moreover, teaching and learning verbal activities and developing a right attitude to it was tedious with chalk and talk method in a classroom of 5075 students. Many a time, the students do not get time and space to get individual attention and they do not know the level of their English competency. Many students grieve because of low confidence regarding their verbal skills and their capability to perform in the verbal tests organized by the Multinational Companies. They feel shattered when they are checked out from their placement opportunities after their aptitude tests. So, in this scenario, it is relevant to use computer technology to teach verbal ability in English. Furthermore, verbal aptitude is tested in the placement drive using computers and for this reason; the student-computer interface is crucial and relevant.

Words are the building blocks of a language. The students should have the silage of words that foster their understanding and answering on internet or intranet verbal tests that are time bound. They are in a position to improve their vocabulary and verbal reasoning using computer technology. So, the paper seeks to find out answers to the following questions: To what extent is computer technology used in classrooms in vocabulary learning? What are the motivating factors that make the students use computer technology in acquiring verbal skills? How far the learning of verbal ability has installed confidence and modified their attitude towards leaning aptitude tests? In what way is the computer aided language learning beneficial to them? So, this paper will be described in temperament. It will describe the extent to which computers are available in colleges and the objectives of using computer technology in classroom instruction, the benefits of using computer-based technology in teaching verbal ability in English as a Foreign Language (EFL) and the attitude change towards verbal texts in a foreign language in south Tamil Nadu and in India in general. The research is done with the students of Engineering colleges in forethought and their mandatory situation to master verbal ability to get them placed.

\section{HYPOTHESES OF THE STUDY}

\section{In Searching for Answers to the Research Questions, the Following Hypotheses are Made}

- The students have willingness to gain vocabulary and verbal ability using computer technology.

- The students are provided with ample opportunities to do computer enabled verbal ability tests.

- The students consider that the use of computer technology enhances the positive attitude in acquiring verbal skills.

- English language students find computer technology as a good learning tool to improve vocabulary. 


\section{Participants}

The participants of this research are the third year undergraduate student of Mepco Schlenk Engineering College, Sivakasi. They were 50 in number, out of which 16 are boys and 34 are girls. The participants from the same class and the same age group were selected as it is easy to group them together and allow them to get trained using the computers. They are from a semi urban area with fair English background. They had their basic studies in an English medium school where lessons are taught and learnt in English and the communication between the faculty and the students were in their native tongue. English remained the language for academic learning and understanding as well as writing of exams. Their confidence level in English competency was very less, as their exposure to English was not adequate. As English is a second language, the participants found the verbal reasons questions to be tougher than other tests. To exhilarate the learning verbal ability in English, the students needed strong motivation.

\section{Motivation}

Motivation refers to a process that insists on the need and leads to a behavior that moves a learner towards accomplishing an aim (Babaee 2012; Melendy, 2008). The issue of motivation is indispensable in EFL contexts such as Indian because motivations towards learning a foreign/second language directly proportional to the teachers' motivation in their verbal classrooms. Babaee (2012), recommends that suitable curricula and virtuous teaching may not be sufficient to assure success because without adequate motivation even learners with the most extraordinary capacities cannot triumph long-term aims. The students from III year Electronics and Communication Engineering of Mepco Schlenk Engineering College, Sivakasi have provided motivation to practice verbal ability unceasingly as a part of English language learning converging towards better placement. The participants are made aware of the fact that verbal ability tests are not only useful for placement, but also to excel in GRE, GMAT, UPSE Exams, bank exams and other competitive Examinations. They realized that a person with a higher verbal ability is better equipped to communicate as they possess good knowledge of English grammar and vocabulary.

\section{Research Design}

The student's interest in receiving verbal ability test is found out using a questionnaire (Annexure I). The students are made to undergo the training tests for four months with a compulsory online verbal ability test for 1-3 hours every week. Then the student's change of attitude towards verbal ability was measured again using another questionnaire (Annexure II). The questionnaire given before the actual training started had six questions. The questions were focused on the readiness of the participants and their basic computer knowledge. They were inquiring of their intention towards computer aided auto-learning using the available sources for verbal ability. They were asked if they feel that online sources can get them access to the native speakers and if the resources accessed through computers are better than their text books. They were asked to speak about the number of hours and the number of times they can access the internet for verbal abilities.

The second set of questionnaire consists of 20 questions related to the usefulness and reliability of the software as well as websites testing verbal abilities. The participants inquire about the reasons for various positive points regarding the quality and quantity of the content, speed, time consumption, the variety of exercises, huge amount of vocabulary exercises available, the immediate feedback/result received, and access to native speakers, auto-learning, appealing aspects like color, graphics, animation, picture etc.., 


\section{Procedure}

In the research on attitude to verbal ability, the participants made use of the language lab with seventy computers connected to the internet. They are provided with the opportunity to do listening tests also as there is a provision of the headphones. They are prepared for various components of verbal tests like reading comprehension, listening comprehension, match the synonyms, antonyms, error correction, Cloze tests, sentence completion etc....

The participants' willingness towards learning the verbal abilities in English is inquired and positive results are received. On the whole, the students are willing to take the vocabulary tests and are confident that they can enrich their verbal skills using internet after being motivated. It is made sure that all the participants have good knowledge of computer skills to do the on-line tests. They are given the proper instruction to use the computer and attempt the questions. The participants are provided chance for learning the vocabulary inside the college and are guided by a faculty. They are made to be aware of the type of question they will have to answer as well as guidelines needed to solve the questions. They are given an orientation towards tackling the verbal ability question, are made to be conscious of the time factor involved in the completion of the test. They are asked to do verbal abilities tests every week and are motivated to learn new words and enrich the vocabulary. They are given many tests so that they can understand the nuances of writing the tests.

The participants are made to be aware of the fact that words are the basic structure of any language and are asked to learn new words of their choice periodically because the students are from different background and so they are encouraged to upgrade the word list in their mind. The students learnt the word of their interest and have got a strong attitude that as they keep adding up words in their mind, they will have a good score in the on-line verbal ability tests. The participants learnt new words periodically and are monitored by the faculty. They are given assignments to enrich vocabulary simultaneously on the days they do verbal ability tests. The participants have the confidence that the educational websites will help them to learn English and a positive attitude related to vocabulary is built on the student.

\section{Outcome}

The participants gave the feedback that the educational websites are attention-grabbing and obliging to build confidence over their language proficiency and competence to solve the verbal ability tests. The feedback made the researcher come out with the decision that $85 \%$ of the student liked the educational websites which afford unsurpassed learning experiences. Improving verbal ability through educational website is very undemanding as well as elevating as the participants have the access to the tests suitable for their level and need. The participants have the preference of deciding on a specific verbal ability test (example: reading comprehension or synonym or antonyms) in which they find themselves to be week after doing a few sample tests.

The participants have strongly agreed to the concept that the computer based verbal ability tests using internet provide them rich learning experience as there is the prospect of accessing a plethora of verbal ability resource. The participants employ a massive amount of on-line vocabulary exercises and succeed themselves trained. As the participants accomplish a large number of verbal tests, the students get familiar with the test patterns and the intricacies involved in finding the solution. As the students perform plenty of verbal ability tests, they are able to get rid of their apprehension towards the language learning. They establish an acquaintance with verbal ability in English and generate an affinity towards getting solution for the quandary focused by verbal ability tests. 
Another attention-grabbing factor that enthralled the participants is the instantaneous feedback they entertain after the completion of the test. The on-line tests are administrated with pre-defined answer in the software. So, after the submission of answer to the multiple choice questions within the allotted time, the participants obtained the result instantly. The feedback is provided promptly unlike the paper based test for which the feedback is provided as per the convenience of the teacher. There is the possibility of lack of accuracy of evaluation of the human being, whereas accuracy is maintained perfectly in the computer based evaluation. These quick feedbacks motivate the participants to undertake more aptitude tests with curiosity and go ahead with mastery of English.

The participants considered that learning verbal ability using computers is quite motivating, as it appeals to the senses and provide dull and tough tests with some kind of interactive scheme. The websites provide different tests behind multiple settings, color, pop-ups that invoke the curiosity of the learners. The graphics and animation and the layout of the website compel the active participation of the learners in acquiring verbal ability. Along with undertaking the verbal tests, the participants involved in various activities related to language acquisition. They showed interest in listening to orations in English, watching videos, focusing on language games and learning pronunciation. Educational websites throw light on the concepts taught in the English classroom.

As it is quite natural that the words have their own impact on acquiring verbal ability, learning new words using computers is also appealing to the participants. As a result, the verbal ability is no more a tedious one, but has become an activity filled with fun. As the learning experience has become happy and comfortable one, the participants are very attentive in their task. They complete the work sincerely without feeling bored. They find the webpage to be more interesting than statistic black and white test pages. The participants are aware of the fact that the electronic media is better than printed media because the text books bind them to the available material within the printed pages whereas the internet provides profuse open sources catering to their requirement. As the lessons are learnt with interest and commitment, the participants are able to retain the new concept words as well as the sentence pattern very well for a long time.

Further, the participants can meet the foreign teachers, who can guide them better than the second language teachers. They have the chance to get opinions and techniques from the native speakers of English and gain learning experience that boost up their confidence. Using software, the students can get their doubt clarified through online chat. The researcher also found the computer based verbal tests to be useful as there is the opportunity of monitoring students' screens as a whole and also on an individual basis from the teacher's workstation. It enables monitoring the students from the teacher's PC whenever they are on self-learning. The lab can be controlled by the language experts/teachers who serve as a gatekeeper for learners. This facilitates the teacher to take control or terminate applications on any student computer when the students go astray from the regular lessons allotted to them and losing focus on the special provisions in the lab.

The students are made to answer some negative questions also to prove that the computer aided verbal ability tests are useless and no concrete learning of English takes place. The participants do not agree with the futility of the on-line verbal tests. They say that, it is not a waste of time and energy to spend time in front of computer for attempting verbal ability test. Moreover, they have denied idea that the online verbal ability tests are boring. They never considered these tests to be difficult. The negative questions strongly prove that the students have an affirmative attitude towards learning English vocabulary. On the contrary, these kinds of tests enhance their positive attitude to verbal learning. 


\section{CONCLUSIONS}

From the analysis of the feedback given by the participants, it has become obvious that the students like to improve their verbal ability using computer technology and in many ways, it is better than learning verbal ability from the text books. The computer technology fascinates the participants by its provision of learning inside as well as outside the classroom. The researcher has arrived at the conclusion that students must be made to be aware of the free online websites, and get trained in verbal ability tests and get a first-rate job as well as high-quality command over the language.

\section{REFERENCES}

1. Guo Wanquan, Yang Yonglin. Foreign Language Teaching Research Review under Virtual Environment. Journal of Liberation Army's Foreign Language Institute, 2002 (3).

2. http://www.ict4lt.org/en/warschauer.htm

3. http://childeducation-journal.org

4. cjnse.journalhosting.ucalgary.ca/ojs2/index.php/cjnse/article/../154

\section{APPENDICES}

\section{Annexure: 1}

Mepco Schlenk Engineering College, Sivakasi

Table 1: Using Computers to Learn English Language Vocabulary and Practicing Verbal Ability Tests

\begin{tabular}{|c|l|l|}
\hline 1. & $\begin{array}{l}\text { Is your English background and experience beneficial to your } \\
\text { English studies? }\end{array}$ & Yes/No \\
\hline 2. & $\begin{array}{l}\text { Do you possess sufficient computer and keyboard skills for } \\
\text { doing online work? }\end{array}$ & Yes/No \\
\hline 3. & $\begin{array}{l}\text { Do you like to use the educational websites to learn English } \\
\text { language vocabulary? }\end{array}$ & Yes/No \\
\hline 4. & $\begin{array}{l}\text { Do you think the use of educational websites enables you to } \\
\text { understand the English language better than text books? }\end{array}$ & Yes/No \\
\hline 5. & $\begin{array}{l}\text { Can you learn how to use Internet resources for learning } \\
\text { English yourself? }\end{array}$ & Yes/No \\
\hline 6. & $\begin{array}{l}\text { Do you feel that the concept learnt in English online classes } \\
\text { will help to remember it better? }\end{array}$ & Yes/No \\
\hline
\end{tabular}

\section{Annexture II}

Mepco Schlenk Engineering College, Sivakasi

Table 2: Using Computers to Learn English Language Vocabulary and Practicing Verbal Ability Tests

\begin{tabular}{|c|c|c|c|c|c|}
\hline Sl. No & Criteria & $\begin{array}{l}\text { Strongly } \\
\text { Agree }\end{array}$ & Agree & Disagree & $\begin{array}{l}\text { Strongly } \\
\text { Disagree }\end{array}$ \\
\hline 1. & $\begin{array}{l}\text { I like to use the educational websites to learn English } \\
\text { language vocabulary }\end{array}$ & & & & \\
\hline 2. & $\begin{array}{l}\text { The educational websites are useful for learning English } \\
\text { language vocabulary. }\end{array}$ & & & & \\
\hline 3. & $\begin{array}{l}\text { The use of educational websites enables me to } \\
\text { understand the English language better than text books. }\end{array}$ & & & & \\
\hline 4. & $\begin{array}{l}\text { The provided educational websites are suitable for my } \\
\text { level. }\end{array}$ & & & & \\
\hline
\end{tabular}



Aptitude using Computer Technology and Internet

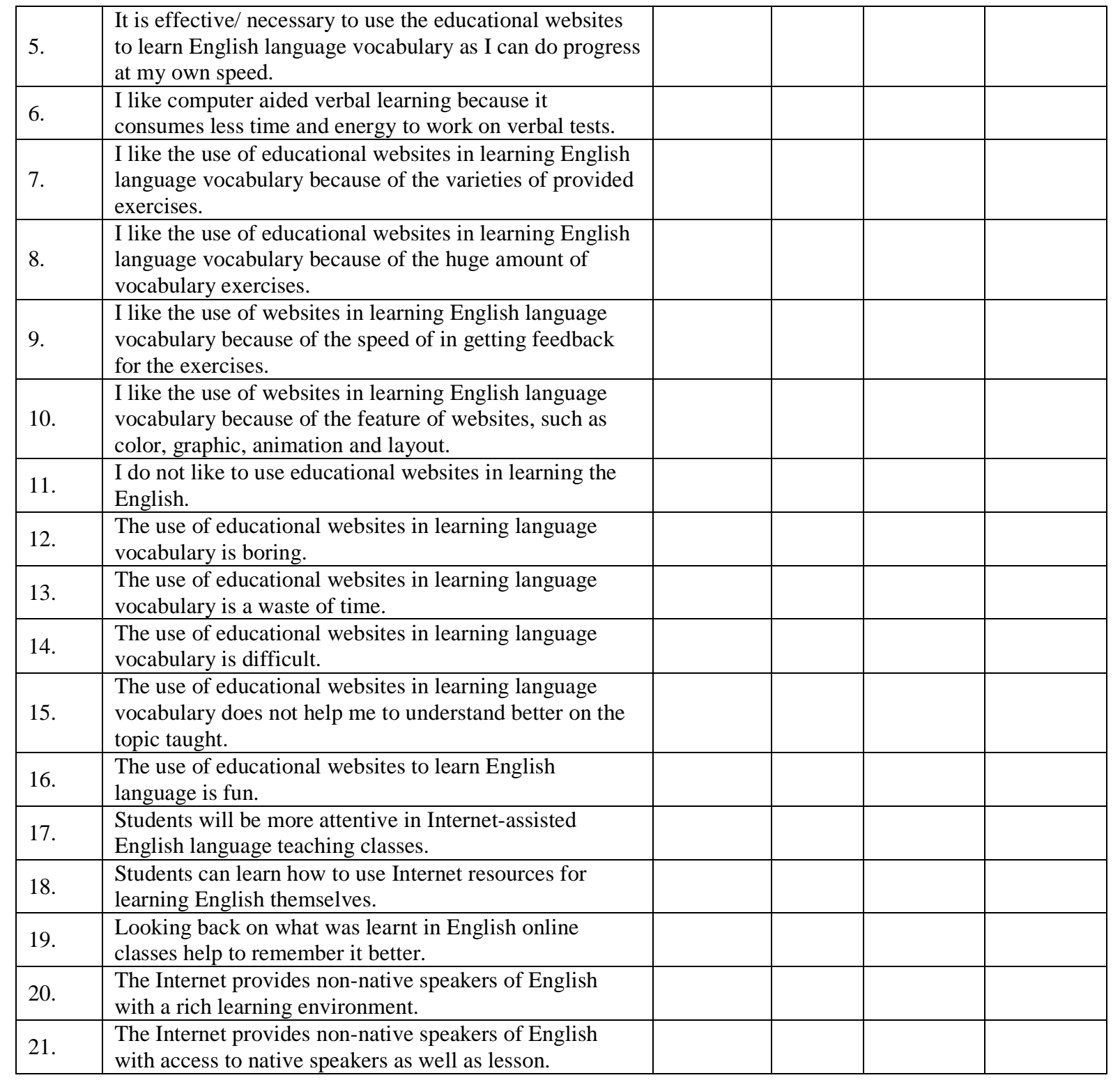


